\title{
Pensamento educacional e intelectuais na história da educação brasileira ${ }^{1}$
}

\author{
Educational ideas and intellectuals in the history of Brazilian education
}

Las ideas educativas y los intelectuales en la historia de la educación brasileña.

\begin{abstract}
Bruno Bontempi Junior - Universidade de São Paulo | Departamento de Filosofia da Educação e Ciências da Educação | São Paulo | SP | Brasil. E-mail: BONTEMPI@usp.br @onci
\end{abstract}

Resumo: O artigo apresenta uma proposta de pesquisa historiográfica sobre os temas "pensamento educacional" e "intelectuais" na produção divulgada nos Congressos Brasileiros de História da Educação (2000-2017). Alternativamente ao "balanço", que enfatiza acúmulos e correntes principais, propõe a elaboração de um "inventário", a fim de identificar e explicar os variantes e diversos modos de apropriação de referências e uso de conceitos. Metodologicamente, compreende-se que a natureza dessas apropriações e usos está referida a fatores múltiplos, tais como a formação inicial dos pesquisadores, a composição e orientação dos programas, linhas e grupos de pesquisa, os convênios nacionais e internacionais etc. A fim de sustentar o argumento, o artigo percorre a formação do campo, procede à crítica dos balanços e investiga os significados do conceito de intelectual e seus usos nas ciências humanas. Conclui, partindo de uma articulação reflexiva sobre esses tópicos, com hipóteses de investigação.

Palavras-chave: Historiografia. Intelectuais. Pensamento educacional.

Abstract: The article presents a proposal of historiographical research on the themes "educational thinking" and "intellectuals" in the production published in the Brazilian Congresses of History of Education (20002017). Alternatively to the "balance", which emphasizes accumulations and main currents, it proposes the elaboration of an "inventory" in order to identify and explain the variants and various modes of reference appropriation and use of concepts. Methodologically, it is understood that the nature of these appropriations and uses is related to multiple factors, such as the initial formation of researchers, the composition and orientation of research programs, lines and groups, national and international covenants, etc. In order to support the argument, the article remarks the formation of the field, criticizes the balance sheets and investigates the meanings of the concept of intellectual and its uses in the human sciences. It concludes, starting from a reflexive articulation on these topics, with research hypotheses.

Keywords: Historiography. Intellectuals. Educational ideas.

\footnotetext{
${ }^{1}$ Este artigo é produto do projeto de pesquisa "Intelectuais e pensamento educacional como objetos da história da educação brasileira", financiado pelo CNPq (Bolsa Produtividade PQ2), processo n. 304757/2017-9.
}

- Recebido em 10 de abril de $2019 \bullet$ Aprovado em 06 de novembro de 2019 • e-ISSN: 2177-5796

DOI: http://dx.doi.org/10.22483/2177-5796.2020v22n1p145-166

Copyright @ 2019. Conteúdo de acesso aberto, distribuído sob os termos da Licença Internaonal da CreativeCommons - CC BY-NC-SA Atribuição Não Comercial (https://br.creativecommons.org/licencas/) - Permite distribuição e reprodução, desde que atribuam os devido créditos à publicação, ao autor(es) e que licenciem as novas criações sob termos idênticos. 
Resumen: El artículo presenta una propuesta de investigación historiográfica sobre los temas "pensamiento educativo" e "intelectuales" en la producción publicada en los Congresos Brasileños de Historia de la Educación (2000-2017). Alternativamente al "balance general", que enfatiza las acumulaciones y las corrientes principales, propone la elaboración de un "inventario" para identificar y explicar las variantes y los diversos modos de apropiación de referencia y uso de conceptos. Metodológicamente, se entiende que la naturaleza de estas apropiaciones y usos se relaciona con múltiples factores, como la formación inicial de investigadores, la composición y orientación de programas de investigación, líneas y grupos, acuerdos nacionales e internacionales, etc. Para apoyar el argumento, el artículo percurre la formación del campo, critica los balances e investiga los significados del concepto de intelectual y sus usos en las ciencias humanas. Concluye, a partir de una articulación reflexiva sobre estos temas, con hipótesis de investigación.

Palabras clave: Historiografia. Intelectuales. Ideas educacionales. 


\section{Introdução}

Há duas décadas, os Congressos Brasileiros de História da Educação (CBHE), promovidos pela Sociedade Brasileira de História da Educação (SBHE), têm se consolidado como a principal reunião científica da comunidade nacional de historiadores da educação. Suas dez edições foram realizadas em todas as regiões do país, sucessivamente nas cidades do Rio de Janeiro (2000), Curitiba (2002), Natal (2004), Uberlândia (2006), Aracaju (2008), Vitória (2011), Cuiabá (2013), Maringá (2015), João Pessoa (2017) e Belém (2019), contando com número crescente de participantes A longevidade e o acúmulo já permitem que sobre sua volumosa produção se proceda à investigação historiográfica, não apenas a respeito do perfil do conjunto das comunicações, no plano quantitativo, mas verticalmente, ou seja, no plano qualitativo do estado da arte sobre os temas e objetos que, por todo o período, capturaram a atenção dos pesquisadores. Os congressos podem ser considerados como termômetros fidedignos das preferências que fomentam a produção em uma comunidade acadêmica, tão mais que os periódicos, relativamente mais seletivos e cujos tempos de gestação são mais longos.

Assentado na hipótese de que as reuniões científicas expressam com mais significativa prontidão e sensibilidade as vogas e tendências instaladas em qualquer campo, submeti ao Conselho Nacional de Desenvolvimento Científico e Tecnológico (CNPq) o projeto de pesquisa "Pensamento educacional e intelectuais como objetos da história da educação brasileira", que foi contemplado com Bolsa Produtividade. O referido projeto pode ser definido como um estudo crítico da produção historiográfica da especialidade nas últimas duas décadas, não em sua totalidade, mas sobre temas em torno dos quais tem se desenvolvido uma produção significativa e relativamente duradoura: o conjunto "pensamento educacional/intelectuais da educação". As perguntas iniciais podem ser sumariadas nas seguintes formulações: quais os modos de fazer e as características próprias da produção sobre “intelectuais/pensamento educacional'?; quais fatores, de diferentes naturezas e pesos relativos, afetaram a trajetória dessa produção nos contextos das edições e do próprio subcampo? Como teriam alterado seu escopo os modismos e as mutações paradigmáticas do campo? Quais são os diferentes usos e apropriações de conceitos, metodologias e referências na composição de um mosaico variado de tratamento desses temas e objetos? 
O modo usual com que perguntas similares têm sido investigadas e respondidas, desde a primeira edição do CBHE, consiste na metodologia dos "balanços", ensaios descritivos que mesclam procedimentos quantitativos e qualitativos a fim de identificar preferências temáticas e teóricas, além de sugerirem a existência de tendências majoritárias dedutíveis de características comuns às comunicações. Neste artigo, pretendo expor os limites do gênero "balanço", considerando o viés dos resultados derivados de sua intencionalidade, sua função inerente e seus procedimentos, propondo como alternativa metodológica o "inventário", cuja virtude seria exatamente revelar a variedade que tem permanecido à sombra nos "balanços". Para tanto, nas duas primeiras seções apresento a pertinência e funcionalidade do gênero "balanço" na história de um campo em formação, marcado pelo primacial conflito de "paradigmas" e pela rápida e consistente expansão da comunidade, que se evidencia no volume crescente de congressistas que passaram a frequentar as reuniões nacionais e internacionais de que a SBHE coparticipa. Em seguida, apresento premissas interpretativas que resultam de uma investigação sobre a organização axial das sucessivas edições do CBHE e esboço um quadro sintético dos significados e dos usos do termo "intelectuais" na história e na sociologia, bem como na "tradição" dos estudos de história e filosofia da educação no Brasil. Por fim, apresento reflexões preliminares sobre o tema, assim como indicações e sugestões de pesquisa, sempre com vistas a compreender a configuração histórica deste campo de estudos.

\section{Expansão, reconhecimento e autoconhecimento da história da educação no Brasil}

É consensual e suficientemente propalado que a história da educação como campo de pesquisa tem crescido grandemente no Brasil. A regularidade das reuniões científicas, a presença e o protagonismo de entidades associativas, a densidade de veículos especializados e a multiplicação dos praticantes e das publicações têm sido sobejamente indicados em artigos e balanços nacionais, binacionais ou locais (VIEIRA et al., 2017). A reflexão sobre a natureza e validade epistemológica do conhecimento produzido, ou seja, a crítica historiográfica, porém, parece não estar acompanhando quantitativa e qualitativamente essa maré montante. É isso, ao menos, o que se constata em indícios como a rarefação do substantivo historiografia entre os termos usados na composição de eixos temáticos no principal evento da especialidade no Brasil 
(BONTEMPI JUNIOR, 2017) e o virtual desaparecimento das resenhas em nossos periódicos, quando muito, substituídas por elogiosas e descritivas notas de leitura.

Mas por que parece estar desaparecendo a historiografia como prática compreensiva e de reflexão crítica sobre a especialidade e sobre o campo? Por hipóteses tem-se o desencorajamento do pesquisador diante do próprio gigantismo da produção e a pacificação política do subcampo, promovida a partir da fundação da Sociedade Brasileira de História da Educação (SBHE), que, atenta a uma política pluralista de acolhimento de diferentes referenciais e modos de escrever a história da educação (SAVIANI et al., 2011), teria acomodado as tendências em conflito desde meados de 1980. Evidentemente, a comprovação da segunda hipótese exigiria prospecções que fogem ao escopo deste artigo. Não obstante, é na suposição de que a historiografia crítica dos anos 1990 tenha tido como mais forte motivação o confronto entre paradigmas sobre o pano de fundo da luta pela hegemonia no subcampo, que sustento a proposição de uma nova onda de historiografia crítica, desta feita, caracterizada pela segmentação e verticalização.

No início da década de 1990, impulsionado por trabalhos acadêmicos que na década anterior já dobravam as grades de ferro das interpretações reprodutivistas e gramscianas da história da educação no Brasil, ganhou proeminência nos principais foros de encontro e publicação de seus praticantes um "movimento de renovação teórica, temática e metodológica" (SAVIANI et al., 2011, p. 18). Esse movimento apontava para o questionamento de modelos e práticas predominantes na escrita da história da educação brasileira, tais como a interlocução quase exclusiva com o Estado, o privilégio dado às fontes oficiais, o interesse pelo estudo do século XX e o referencial teórico e metodológico que, majoritário nas instituições produtoras dessas narrativas, dava o tom dos programas de pós-graduação em funcionamento desde os anos 1970 (BONTEMPI JUNIOR, 1995).

O texto de Clarice Nunes e Marta Carvalho (2005), divulgado pela primeira vez na $15^{\mathrm{a}}$ Reunião Anual da ANPEd, em 1992, aparecia como antítese aos modos usuais de conceber a história e as práticas do ofício de historiador da educação até meados dos anos 1980. Tornou-se, por sua ênfase e enfoque, um manifesto por uma nova história da educação, centrando articuladamente o foco no questionamento da usual concepção de fontes e no "exame das perspectivas abertas e dos desafios lançados pela nova história cultural para a pesquisa em história da educação" (NUNES; CARVALHO, 2005, p. 19). Em suma, propunha que os 
pesquisadores assimilassem o léxico, o temário, as ferramentas conceituais e a concepção de fontes da chamada Nova História Cultural, "no intuito de construir uma historiografia menos generalista e estereotipada" (NUNES; CARVALHO, 2005, p. 18). A referida historiografia, representada como sedimentação ou justaposição de inspirações originais cristãs da disciplina com práticas historiográficas "positivistas", era precisamente a dominante nos programas de pósgraduação em educação, reconhecida como "marxista", . A partir daí, aglutinou-se e ganhou força no Grupo de Trabalho de História da Educação da Associação Nacional de Pós-Graduação e Pesquisa em Educação (ANPEd), a tendência reconhecida como "nova história cultural" na historiografia da educação brasileira.

Em 1986, surgira o Grupo de Estudos e Pesquisas História, Sociedade e Educação no Brasil (HISTEDBR), que, em evidente contraponto à insurgência de novos paradigmas, dispunha-se a "investigar a História da Educação pelas mediação da Sociedade" (SAVIANI, 1998, p. 14), além de promover a discussão teórico-metodológica e a crítica das novas concepções historiográficas e de seus pressupostos. Na contramão da tendência que avançava na ANPEd, o grupo, sediado na Faculdade de Educação da Universidade de Campinas, visava a combater o avanço da Nova História Cultural, que se apoiava em produção destoante de seus cânones e que vinha procedendo à crítica dos resultados das pesquisas históricas de orientação marxista na educação brasileira. Dermeval Saviani (1998, p. 14), seu fundador e principal expoente, afirmou que o grupo fora criado em contraposição à "tendência que começava a invadir o campo da historiografia educacional”. A escolha do verbo denota a postura defensiva com que o grupo lidou com a ameaça da perda de hegemonia sobre o subcampo da história da educação.

A tensão que passou a existir entre os praticantes e prosélitos desses dois modos de fazer e pensar a história da educação exigiu, desde logo, medidas de ordem institucional. Com efeito, Clarice Nunes (1990 apud CATANI; FARIA FILHO, 2005, p. 94), durante a $13^{\text {a }}$ Reunião Anual

\footnotetext{
2 As primeiras críticas à historiografia "marxista" aparecem em 1984, em seminário organizado pelo INEP, que marcou o início do processo de reflexão sobre as bases teórico-metodológicas, os procedimentos e, sobretudo, a validade dos resultados e o alcance da produção de conhecimento em história da educação brasileira. A publicação derivada deste encontro, Em Aberto, traz duas contribuições que se destacam pela intensidade crítica aos modos e resultados dessa historiografia. Jorge Nagle e Mirian Warde convergem em suas avaliações sobre a produção que, surgida nos anos 1970, irradiava-se dos programas de pós-graduação da área: reconhecem que as "determinações econômicas, sociais e político-ideológicas" a que se recorria para produzir o contexto de inserção do objeto educacional não passavam de uma justaposição de fatores da realidade social aos traços que caracterizavam a educação em dado momento histórico.
} 
da Anped, apontou como desafio de sua coordenação do Grupo de Trabalho História da Educação "compatibilizar quadros teóricos que têm um ritmo, uma densidade, enfim, uma história diferente". Em 1997, durante seminário realizado em Campinas, por iniciativa do HISTEDBR, Saviani identificaria o paradigma insurgente como pós-moderno, em contraposição ao iluminista ou racionalista, a que se filiariam o positivismo, o marxismo e as duas primeiras fases da Escola dos Annales (SAVIANI, 1998).

$\mathrm{Na}$ reconstituição dos passos que deram configuração ao campo, essa tensão original, marcada pela contraposição de tendências teórico-metodológicas, tem sido minimizada em prol da ênfase nos efeitos pacificadores da Sociedade Brasileira de História da Educação, surgida em 1999, cuja maior virtude teria sido fazer convergir os dois litigantes em prol do crescimento da comunidade de praticantes e do avanço quantitativo e qualitativo da produção e da representatividade (SAVIANI et al., 2011). De fato, a composição mista das chapas de presidência da entidade, em seus primeiros anos, denota o intuito de acomodar politicamente as correntes por meio da distribuição equilibrada de poderes no subcampo.

No universo da produção e divulgação de conhecimento em história da educação brasileira, entretanto, qual tem sido o papel e o peso relativo dessas correntes na definição de temas, na conformação de objetos de estudo e no estabelecimento de narrativas e interpretações sobre a experiência histórica da educação e seus agentes no Brasil? A resposta não se encontra facilmente nos balanços da especialidade, para os quais a hegemonia da Nova História Cultural, manifesta no acúmulo de citações de autores associados, no uso de seu léxico e nas escolhas por determinados objetos parece ter relegado o marxismo ao desaparecimento ou à incorporação resignada dos cânones do antagonista (BASTOS, BENCOSTA; CUNHA, 2005) ${ }^{3}$. Suponho, porém, não ter havido superação de um paradigma por outro, nem que se tenha completado uma acomodação. Por isso mesmo, as duas tendências têm se mantido, trilhando caminhos paralelos. Esse paralelismo se expressa, por exemplo, nas escolhas que os praticantes têm feito dos veículos de divulgação de pesquisas. Em levantamento feito em 2014, junto à Revista Brasileira de História da Educação (RBHE) e à Revista do HISTEDBR On-line, constatei que 22 autores

\footnotetext{
${ }^{3}$ Em balanço sobre a pesquisa em história da educação na Região Sul, esses autores assentam que "o enfoque teórico é bastante diversificado e abrangente, mas reflete os avanços que têm sido desenvolvidos na área e na pesquisa histórica. De maneira abrangente, é possível afirmar que se direcionam para a 'nova história', com abordagens na perspectiva de uma história cultural, superando abordagens tradicionais (positivistas) e algumas interpretações marxistas, de natureza mecânica e reducionista" (p. 259).
} 
haviam publicado em ambas as revistas, ou seja, 9,4\% dos 234 que publicaram ao menos uma vez na primeira e apenas $2,7 \%$ dos 814 que publicaram na segunda. Assim, ainda que a RBHE seja o veículo de uma associação que pretende propiciar o cultivo da crítica e do pluralismo teórico, ela efetivamente não tem congregado equilibradamente as tendências, posto que uma delas prefere o periódico de sua própria entidade, tanto quanto sua própria reunião científica.

\section{Balanços ou inventários?}

Embora formalmente se pareçam com estudos historiográficos e adotem categorias de análise consagradas nesses trabalhos (WARDE, 1984; BONTEMPI JUNIOR, 1995), os balanços da especialidade, como já apontaram seus críticos (GONDRA, 2007; SAVIANI, 2007; ASCOLANI, 2007), padecem de incompletude e superficialidade. Ainda que sejam dignos os esforços de seus autores de oferecer uma visão panorâmica da especialidade, deles costumam resultar mapeamentos "inicia[is] e, necessariamente, provisório[s], da investigação na disciplina" (VIDAL; FARIA FILHO, 2005, p. 172) e "mais perspectivas para serem trabalhadas do que conclusões" (CATANI; FARIA FILHO, 2005). Em regra, finalizam com uma "inconclusão" (BASTOS; BENCOSTA; CUNHA, 2005, p. 265) e o "convite para que outros trabalhos se debrucem sobre a questão" (VIDAL; FARIA FILHO, 2005, p. 213). Sua incompletude se deve, em parte, às próprias condições de produção: diante da proposta de comissões científicas ou coordenações de grupos de trabalho, os designados têm de lidar com muitas informações, nem sempre de fácil acesso, a serem organizadas em pouco tempo de trabalho e reflexão. Dispondo de resumos de comunicações (ALVES, 1998), capítulos iniciais das dissertações e teses (ARAÚJO, 2005) ou mesmo títulos de trabalhos acadêmicos (VIDAL; FARIA FILHO, 2005) os recenseadores não têm conseguido distinguir mais do que a pluralidade de temas, o uso de variadas fontes, a tendência de periodizar segundo o objeto etc. Recorrendo à contagem por categorias e à conversão de números absolutos em percentuais, pretende-se que os acúmulos, ainda que confessadamente parciais e inconclusivos sejam interpretados como tendências centrais, cuja devida apuração demandaria o recurso à estatística descritiva. O caráter dinâmico, implícito na noção de tendência, esvai-se; fica a fotografia, posada e bidimensional, na qual os mais altos ocupam a primeira fila. Em suma, testemunha-se o vertiginoso aumento dos 
praticantes e seus produtos a par do triunfo da Nova História da Educação, rebento polimorfo do movimento crítico de fins dos anos 1980 sobre certa "historiografia tradicional".

Os indicadores preferidos nos balanços, tais como temas, periodização e referenciais proclamados pouco ou nada têm a dizer, entretanto, sobre o modo como as tendências têm lidado com sua acomodação no campo, no que se refere à distribuição e legitimação dos resultados de pesquisa. Primeiramente, por trabalharem com indicadores e metodologias díspares, não permitem a síntese global que levaria à reflexão crítica ${ }^{4}$. Além disso, por não relacionarem os resultados com fatores históricos intervenientes (indução governamental, ações coordenadas em projetos temáticos ou convênios, composição do quadro docente dos programas etc.), com as tradições, os objetivos declarados ou com os fatores da realidade histórica a que se apela para a explicação do fato educacional, os balanços, embora anunciem como função "realizar a crítica do conhecimento, a partir da análise dos métodos, dos objetos e dos lugares e das condições de produção da historiografia da educação brasileira", atendem bem mais ao objetivo de "contribuir para a formação de memória/identidade do campo" (VIEIRA; GONDRA, 2005, p. 13).

Se os balanços têm sido inconclusivos, como então se podem identificar as tendências do que vem sendo publicado em história da educação no Brasil? Será preciso, acredito, encontrar um meio de retomar o esforço historiográfico, entendido como reflexão crítica e diacrônica da produção da pesquisa e escrita em história da educação, articulada às condições efetivas de realização e divulgação desses trabalhos, seja no quadro institucional de formação e atuação dos docentes e discentes autores, seja no sistema de oportunidades de publicação de resultados em reuniões científicas e veículos especializados e, ainda, no diagrama de distribuição de capital simbólico e exercício do poder no campo que a especialidade conforma. A delicada tarefa de investigar esses tópicos cabe à historiografia, prática fundamental para que esta seara de estudos progrida e reflita sobre seus resultados e deficiências, mas que hoje mingua, desencorajada por uma produção gigantesca, dispersa e repetitiva que têm nos balanços seu gênero metacrítico por excelência.

\footnotetext{
${ }^{4}$ Para uma ideia dessa dificuldade, um dos balanços operou a catalogação dos autores citados nos trabalhos segundo sua especialidade, criando categorias como "autores das ciências humanas", "historiadores", "historiadores da educação". Sua inaplicabilidade se expressa, por exemplo, na classificação de Caio Prado Jr. como "autor das ciências humanas", mas não como historiador, e na de Anísio Teixeira como "historiador da educação" Diferenças sutis, tais como as que tangem à delimitação temporal, são usualmente dissolvidas em faixas pré-estabelecidas.
} 
A abordagem que sugiro não representa novidade metodológica: trata-se de, tomando o caso de um domínio temático, inquirir um conjunto de trabalhos para identificar como teria se manifestado a pretensa substituição de paradigmas, as modalidades de uso de referenciais, instrumentos e fontes adventícios de outras áreas de conhecimento ou domínios da história, as alterações no quadro institucional da pesquisa em história da educação no Brasil (por exemplo, o crescimento quantitativo dos praticantes, a nucleação e a regionalização), além de outras variáveis pelas quais se verifiquem também as permanências de modos de escrever a história da educação que hoje são proclamados "tradicionais" ou "superados", mas que de fato resistiram e ainda resistem às "inovações".

A diferença fundamental com relação aos "balanços" residiria, portanto, na intenção de reunir as comunicações em torno de "pensamento educacional/intelectuais da educação" apresentadas nas edições do Congresso Brasileiro de História da Educação (CBHE), de 2000 a 2017, em um inventário analítico, pelo qual não só as similitudes sejam agregadas para produzir números significativos, mas as diferenças e variedades de apropriação e uso de referenciais, metodologias e conceitos associados à abordagem das ideias e dos intelectuais se façam visíveis e passíveis de descrição e interpretação. Como os inventários demandam minúcia, é preciso que os dados a integrar a análise extrapolem as quantificações e transcendam o conteúdo "interno" das comunicações, agregando fatores "externos" que, por hipótese, estendem sua força inibidora ou criativa sobre o pesquisador individual. Esses fatores serão apresentados na seção subsequente.

\section{Premissas de partida e ensaios interpretativos}

Uma panorâmica concisa do subcampo permite afirmar que desde a década de 1980 a maioria dos trabalhos em história da educação tem sido produzida por docentes e discentes dos programas de pós-graduação em educação, muitos dos quais dispõem de linhas de pesquisa na especialidade, e que seus principais veículos têm sido teses, dissertações, artigos e comunicações em congressos, além de livros. A história da educação tem a produção arbitrada e avaliada em padrões estabelecidos pela comunidade científica junto a agências de fomento e indexadores internacionais, sendo que quatro periódicos especializados de alta qualidade concentram a maior 
parte da produção ${ }^{5}$. Os praticantes têm se filiado a entidades representativas próprias, tanto de caráter regional como nacional que realizam eventos e mantém periódicos. Em seus eventos, congregam-se para divulgar resultados de pesquisas, debater temas comuns, definir a "política externa" e organizar o poder interno, fazendo deles uma espécie de "termômetro", não só porque revelam os temas em alta e as vagas teóricas comuns aos praticantes, mas porque indiciam em sua organização a lógica de um campo que goza de relativa autonomia para regular a produção, hierarquizá-la e recompensá-la com títulos, poder institucional, fomento etc.

Para os historiadores brasileiros da educação, os eventos em escala nacional e internacional mais importantes têm sido os congressos Iberoamericano - CIHELA, realizado desde 1992, Luso-Brasileiro - COLUBHE, desde 1996, Brasileiro - CBHE, desde 2000 e International Standing Conference for History of Education - ISCHE, desde 1979, mas na agenda dos brasileiros desde a década de 1990. Os Congressos Brasileiros de História da Educação são os principais fóruns da comunidade nacional, promovidos pela Sociedade Brasileira de História da Educação, entidade nacional, motivo pelo qual podem ser considerados como representativos da produção global. Com suas dez edições, o CBHE já possui uma história a ser narrada, que inclui a trajetória percorrida pelos temas "pensamento educacional" e "intelectuais da educação".

No I Congresso Brasileiro de História da Educação, realizado no Rio de Janeiro, em 2000, a classificação dos trabalhos em oito "subtemas" foi feita a posteriori, uma vez que no ato da inscrição "não foi solicitado que os próprios autores localizassem seus estudos nos subtemas indicados" (SAVIANI, 2000, [s/p.]). Nas edições subsequentes, a escolha dos "eixos temáticos" (definidos em assembleia geral da SBHE) para a inscrição de trabalhos tem ficado a cargo dos participantes. De todo modo, na divisão de oito subtemas havia "Pensamento educacional", rubrica sob a qual se convencionou dispor os trabalhos sobre um autor de ideias educacionais, um pedagogo, um reformador etc. Por isso, "Pensamento educacional" pode ser considerado como predecessor dos eixos que adiante concentrarão, nas reuniões do CBHE, os trabalhos sobre “intelectuais", de vez que esse termo não apareceu na edição de 2000 (XAVIER, 2001).

Em 2002, com o desaparecimento de "Pensamento educacional", surge o termo "intelectuais", associado à "memória da educação no Brasil" na composição de um dos eixos. Na edição seguinte, porém, nenhum dos dois esteve presente. A partir de 2006, o termo

\footnotetext{
${ }^{5}$ Refiro-me à Revista Brasileira de História da Educação, à Revista de História da Educação, à Revista do HISTEDBR On-line e aos Cadernos de História da Educação.
} 
"intelectuais" tornou-se permanente na disposição dos eixos, como que indicando sua plena admissão na história da educação. No CBHE de 2006, surge como "Intelectuais, pensamento social e educação"; em 2008, como "Políticas educacionais, intelectuais da educação e pensamento pedagógico"; de 2011 a 2015, com a invariância quase total do quadro de eixos, manteve-se como "Impressos, intelectuais e história da educação". Na edição de 2017, quando os eixos passaram por significativa reformulação, recebeu o título de "Intelectuais e projetos educacionais". É significativa a variação das combinações, pois, conforme o enquadre, não só o termo recebe outros significados e se presta a associações com os mais variados objetos, como na ocasião dos eventos altera-se o próprio ambiente dialógico, neste caso, as sessões de comunicação.

Perseguir, dentre o vasto conjunto de temas à disposição, a trajetória das comunicações alocadas sob as rubricas "Intelectuais" e "Pensamento educacional" nos Congressos Brasileiros de História da Educação não é uma escolha arbitrária. Ela atende, por certo, à minha familiaridade com o estado da arte, mas deriva do fato de a assunção do universo teórico e metodológico em que orbita o objeto "intelectuais" ter um débito relativamente menor do que outros objetos ou noções, tais como "cultura escolar" ou "impressos pedagógicos" com a voga da "nova história cultural", tendendo a se aproximar da história política (VIEIRA, 2015). Por essa característica, pode-se supor que os eixos que contêm o termo sejam um espaço mais ecumênico, em que as tendências possam aparecer bem representadas, do que os que trazem sinais mais marcados de pertença às referências-guia das tendências dominantes. Cabe, por isto, fazer um percurso introdutório ao conceito e a seus usos, de modo a projetar seus possíveis significados e desdobramentos no corpus que se pretende cotejar.

\section{0 conceito de intelectual: significados e usos variados}

Como a história vem a ser a descrição do individual por meio dos universais (VEYNE, [s/d.], p. 120), o historiador opera com conceitos das ciências humanas, submetendo-os à prova da circunstância, ou seja, esvaziando-os ou enchendo-os de significados que possam servir à narrativa e à construção da interpretação. O caso do conceito de intelectual, é, por seu uso pelos historiadores, ilustrativo da atitude própria ao ofício. Em primeiro lugar, porque não escapa à contingência de ser uma expressão do senso comum, de modo a carregar consigo camadas de 
significados que intuitivamente lhe atribuímos. Como aponta Veyne (s/d.), referindo-se ao conceito de "revolução", embora saibamos o que seja uma revolução ou uma rebelião, não somos capazes de definir esses termos com precisão. Conceitos são sempre, segundo o autor ([s/d.], p. 125), "representações compósitas que dão a ilusão da intelecção, mas que na realidade não passam de espécies de imagens genéricas". Ao folhear trabalhos sobre o tema pode-se admitir de pronto que, à parte questões disciplinares e tradições nacionais, há uma inquietante amplitude de procedimentos: ora se estende o conceito às mais variadas épocas e culturas para indicar os tipos sociais que nelas preencheram uma função necessária a qualquer sociedade, ora se estabelece o nascimento dos intelectuais nas mais diferentes datas e locais, ora reduz-se a tal ponto a abrangência do termo que nada que esteja fora desse lugar e momento possa ser assim designado.

A amplitude dos usos varia segundo uma série de fatores, dentre os quais as projeções valorativas dos autores e as diferentes identidades e estatutos conhecidas por este tipo social no correr da história. Quanto ao primeiro tópico, ao menos desde o historicismo a presença dos valores na produção do conhecimento em ciências humanas, nas quais o homem é tanto o observador como o observado, é vista como incontornável. A despeito da orientação positivista de tratamento dos fatos sociais como coisas, à imitação das ciências naturais, Weber (2000), com o objetivo de se contrapor ao fatalismo e dirigismo da economia política, combinou de um modo sui generis positivismo e historicismo. Admitia que os valores específicos de uma época, nação ou fé religiosa fundamentam a escolha dos fenômenos sociais e históricos pelo estudioso, mas postulava a neutralidade axiológica das ciências sociais, recomendando o rigor metodológico como antídoto à influência dos valores na interpretação dos dados.

Adaptando a sugestiva imagem criada por Löwy para a crítica da "positivização do marxismo" (1996, p. 44), a proposta de Weber equivaleria ao recurso do Barão de Münchhausen, que, afundando no pântano consegue salvar-se ao puxar com as mãos os próprios cabelos. Não há como evitar a intervenção dos valores na produção do conhecimento sobre o homem e a sociedade, ainda que alguns exageros opiniáticos possam ser evitados, especialmente, pelo oferecimento ao leitor dos instrumentos pelos quais se pôde chegar às conclusões apresentadas. Não obstante, o que parece frustrante para alimentar os sonhos de objetividade torna-se estimulante para o historiador que, indagando sobre as escolhas dos que produzem o conhecimento em cada época histórica, pode, pelo avesso, ter acesso a seus valores e suas visões 
de mundo. Assumindo, quanto ao tópico da história dos intelectuais, o caráter inexorável da interferência dos valores ao menos na escolha dos objetos do cientista social, concordo com Burke (2003, p. 25-26), para quem os desacordos quanto à definição do intelectual e seu surgimento não só "revelam uma importante diferença de opinião sobre o peso relativo da mudança e da continuidade na história cultural da Europa", como, em certos casos, manifestam o desejo de retornar ao passado "em busca de pessoas mais ou menos semelhantes a nós mesmos".

Há uma questão insistente a respeito da noção de intelectual, que, considerada em termos weberianos inscreve-se entre os domínios do ser e do dever ser, neste caso, entre o que é possível ao historiador e cientista social reconstruir e analisar segundo exigências metodológicas e o que é significativo para a definição da ética para as intervenções do homem de ação. Certa sociologia, focada na relação entre intelectuais e política, define o intelectual como aquele que se distancia do mundo para sobre ele exercitar a crítica, usando as ferramentas do seu ofício, e esta é uma das vertentes pelas quais transitam alguns estudos em história da educação a respeito de intelectuais. Como afirmam Bastos e Rêgo (1999, p. 5), crê-se que seria “intrínseco à condição intelectual o vínculo entre a atividade de pensar e o empenho moral do analista na elevação da condição humana". Se não for isto, se não for aplicado na crítica, então ele não exerce a função de intelectual e, portanto, não o é. Se essa definição, por ter um olho focado na política tem a vantagem de diferenciar a noção de intelectual da de "homem de letras" ou "de saber", preferida em estudos que incidem sobre produção e difusão do conhecimento, tem em contrapartida o ônus do juízo de valor implícito.

Ao usar este critério para identificar uma personagem do passado como "intelectual", o historiador já estaria lhe apegando uma adjetivação positiva, posto ser esta qualidade o sinônimo da realização de um ideal ético e moral, uma visão de mundo da qual compartilha. Por seu caráter paradigmático, a definição presta-se mal a que se identifiquem e caracterizem os "intelectuais" na história, seja porque esta figura raramente se encontra em sua pureza, seja porque essa definição nasceu entre o final do XIX e o século XX como projeção idealista e retrospectiva para o XVIII, em que teria surgido uma "nova figura social [...] dotada de certa autonomia e razão crítica em relação aos poderes instituídos" (BASTOS; RÊGO, 1999, p. 10) e associada às noções burguesas de espaço público e opinião pública. A transposição da categoria para a reconstrução do passado remoto encontra, todavia, obstáculos. Burke (2003) afirma, a propósito, que a maioria dos 
primeiros letrados europeus modernos não atenderia à expectativa de autonomia e flutuação com relação aos vínculos sociais e institucionais, posto que as universidades que os abrigavam dependiam diretamente da Igreja, e que a maioria deles era membro do clero.

Para uma tal acepção soa como excêntrico o título Os intelectuais da Idade Média [1957], pelo qual Le Goff transcende para tempos bem mais remotos os limites em que se pretendiam encontrar os nossos antepassados. Certamente, a ousadia de Le Goff (2003) contribuiu, como aponta em prefácio para a edição de 1985, para que a noção fosse estendida à Idade Média e até mesmo à sociedade antiga. Para Le Goff (2003), a figura do intelectual como tipo sociológico não surge com os iluministas do século XVIII, mas no ambiente da cristandade ocidental na virada dos séculos XII e XIII, cujos traços essenciais são a divisão do trabalho, a cidade, as novas instituições e um espaço cultural comum que não mais correspondia à repartição geográfica e política da Alta Idade Média. Para o historiador francês, a ligação com a cidade é o elemento decisivo no modelo do intelectual medieval, considerando que a evolução escolar do sistema monástico fechado para o aberto, que inclui o leigo, estaria indissociavelmente inscrita na revolução urbana que marca a passagem do século X ao XIII na Europa Ocidental. A "camada intelectual" destaca-se do corpo estamental da sociedade medieval à medida que seus membros se tornam "homens de ofício", uma corporação de mercadores de palavras que, em busca de distinção, procura livrar-se de sua origem similar à dos trabalhadores manuais. Há, no caminho da promoção social e do poder, o aproveitamento do caminho institucional permitido aos nãonobres (a universidade) para a conversão em altos funcionários, configurando o que Gramsci denominaria "intelectuais orgânicos" da aliança Igreja e Estado. Para Le Goff (2003, p. 9) esses homens não foram necessariamente "críticos", mas nem por isso se excluem da categoria.

Do alto de sua Sociologia dos intelectuais, Leclerc (2004, p. 28), porém, acusa Gramsci e Le Goff de anacronismo por identificarem intelectuais na Idade Média, denominando a aplicação que fizeram do conceito de "assimilações metafóricas que não poderiam ser tomadas ao pé da letra”. Leclerc (2004, p. 28) brande uma definição mais específica, na qual o nascimento dos intelectuais seria "correlato à secularização da sociedade, da política e da cultura no continente europeu”. Segundo sua explicação, “os intelectuais estão ligados à modernidade, isto é, ao secularismo, ao pluralismo religioso, ao nascimento das liberdades de pensamento e de publicação codificadas no final do século XVIII pela Revolução Francesa, sob a expressão 
‘direitos do homem"” (LECLERC, 2004, p. 29). É evidente que a noção é tão restritiva temporalmente quanto culturalmente, de modo a não permitir o uso para profissionais da escrita e do pensamento que não apresentem esses requisitos. É certamente paradoxal que, justamente quando estes homens se estabelecem e são reconhecidos como grupo social relativamente autônomo, inclusive pela afirmação dos ofícios característicos na vida societária urbana, que boa parte se veja destituída do rótulo, porque o intelectual legítimo passa a ser designado por uma determinada posição institucional ou diante dos poderes e uma inclinação psicológica, ou vocação.

A extensão temporal da noção em Le Goff diverge substantivamente da vertente francesa de história dos intelectuais, representada por historiadores como Jean-François Sirinelli, Paschoal Ory e Cristophe Charle, além do sociólogo Michel Winock. Nesta, o alcance do termo é ainda mais restrito, posto que sela o surgimento dos intelectuais na França nos últimos anos do século XIX, quando os homens de letras e de cultura transcenderam sua condição em direção às questões da política e passaram a ser reconhecidos como um novo corpo político na sociedade francesa. O que essa vertente traz, contudo, de mais importante para a definiçãa e para a operação histórica é, além da convergência para a nova história política, o assentamento da condição do intelectual como um estatuto, portanto, implicando visibilidade e reconhecimento social, assim como a superação da dicotomia valorativa entre os grandes pensadores e os divulgadores, que leva à extensão da categorização para um conjunto mais numeroso de formadores de "massas de ar culturais" (SIRINELLI, 1996). De modo mais restritivo, mas benéfico relativamente à concepção gramsciana, que circunscreve a função intelectual a certa capacidade técnica e organizacional, adota um critério que define os sujeitos da investigação, sobretudo, pelo domínio e uso do código escrito e seus meios. Com o acréscimo da inclinação política, mais propriamente, do relativamente frequente imiscuir dos homens de saber na esfera do político, torna-se a questão mais complexa, uma vez que a definição tende a abarcar a interseção entre o mundo do saber, a cidade das letras, e o mundo da política, a face pública que relaciona saber e poder.

No caso da historiografia da educação brasileira, dois obstáculos têm de ser superados quanto ao "ser e dever ser", que estão relacionados a seu desenvolvimento como disciplina e área de estudo. Em primeiro lugar, tendo nascido como irmã xifópaga da filosofia, e ambas, filhas da pedagogia, a história da educação delineou o ensino sobre os "intelectuais" na história da 
educação como o estudo dos grandes pedagogos que supostamente fizeram avançar por todo o passado as práticas e as doutrinas educacionais, frise-se, de interesse para a resolução de problemas da realidade presente. Evidentemente, essa teleologia "pragmática" e com signo de progresso operava na seleção dos sujeitos a serem incluídos no panteão e implicava a análise do valor e da propriedade de suas formulações e objetivações para a resolução de problemas práticos e para a "evolução" das ideias pedagógicas. O estudo dos pedagogos era o estudo dos portadores do "pensamento pedagógico", em suas relações cumulativas com o pensamento antecedente, colhidas as principais "contribuições” para a pedagogia atual. Outra consequência da vinculação da história da educação com a filosofia e com a pedagogia é a tendência, tida como "vício" por Lopes e Galvão (2001, p. 30), de cogitar antes o que deveria ser a realidade educacional, e não o que ela é (ou teria sido), de que se desdobra o lugar-comum da perene incompatibilidade entre as supostas exigências da realidade e as figurações do pensamento.

A partir dos anos 1950, o panorama foi modificado com as diretrizes para a pesquisa histórica implantadas por Laerte Ramos de Carvalho na cadeira de História e Filosofia da Educação da Faculdade de Filosofia, Ciências e Letras da Universidade de São Paulo e continuadas por algum tempo na Faculdade de Educação. Tais diretrizes incluíam a valorização da pesquisa com fontes documentais, mas, principalmente, o exercício de perspectivas "compreensivas" do passado, nas quais os homens, suas ações e ideias não fossem julgados pelo que tivessem contribuído para a realização do devir inerente à história da humanidade, mas interpretados, tanto quanto possível, segundo os sentidos experimentados e representados pelos agentes em seu tempo (BONTEMPI JUNIOR, 2015). Nos anos 1970 e 1980, porém, com o predomínio da historiografia da educação de extração marxista, a incompatibilidade entre o ser e o dever ser, o pensamento dos educadores e a história tendia a ser vista como efeito da representação invertida da realidade, ou seja, como uma ideologia que a velava ou distorcia, sendo tomada ora como objeto da manipulação hábil por pedagogos-ideólogos contra as classes dominadas, ora como restrição do pensamento devido aos prejuízos de uma visão de mundo limitada pela condição de classe do enunciador. O intelectual aparecia, assim, no melhor caso, como consciência-limite de sua classe e, no pior, como produtor e difusor de uma ideologia que tinha em vista a manutenção das relações de dominação (BONTEMPI JUNIOR, 1995). 
O desenvolvimento desta tendência em pesquisas sobre "pensamento pedagógico" trouxe a instalação de tribunais para o julgamento e a condenação dos educadores brasileiros identificados com o "escolanovismo", como Fernando de Azevedo, Anísio Teixeira e Lourenço Filho. Houve, aliás, todo um esforço da historiografia que a sucedeu para restabelecer estudos mais "compreensivos" desses intelectuais, alguns dos quais, até pelo montante de energia empregado nos "resgates", transbordaram em apologias que ainda dominam os intuitos dos pesquisadores atuais ao escolherem intelectuais da educação como objetos, carregando-os de beatitude e pioneirismo. Tende-se a confundir o valor dos resultados da pesquisa com a valorização de suas personagens.

Na mais recente historiografia brasileira da educação, o tema dos intelectuais tem sido dominantemente tratado à luz de dois referenciais: a sociologia de Bourdieu e a Nova História Cultural. Reputo a contribuição de Bourdieu como importante, uma vez que sua teoria do campo questiona a possibilidade de estabelecer uma relação direta e imediata entre a biografia individual ou a "classe social" de origem e a obra, ao postular homologia entre o espaço das obras e o espaço dos produtores e das instituições de produção e divulgação. As operações exigidas pela aplicação da noção de campo exigem bem mais do que a sequência evolutiva das obras e escolas de pensamento e, no âmbito externo, a exposição do surrado "contexto". Elas requerem a “apreensão estrutural” do autor, definido

[...] quanto às suas disposições e tomadas de posição, pelas relações objetivas que definem e determinam sua posição no espaço de produção e que determinam ou orientam as relações de concorrência que eles mantém com os demais autores e o conjunto das estratégias, sobretudo formais, que o torna um verdadeiro artista ou um verdadeiro escritor (BOURDIEU, 1990, p. 177-178).

Cabe evitar, entretanto, a empolgação pelas estruturas e tentar restituir à história não só o indivíduo como também o evento, que tendem a desaparecer, uma vez que o sujeito passa a manifestar em sua obra e em seus deslocamentos pelo campo uma disposição para a ação que se tornou a estrutura incorporada. $\mathrm{O}$ desaparecimento do sujeito, sua moldagem ou subjugo segundo estruturas poderosas como a cultura e a linguagem também se promove em abordagens afetas à Nova História Cultural, que, sob inspiração foucaultiana, entendem a cultura como poder e concebem o indivíduo como um efeito do poder e como seu centro transmissor (SAHLINS, 2006). Nessa tendência, que aposta na alta eficácia dos dispositivos, preferencialmente palpáveis, 
o "intelectual" tem sua figuração no exame da "função autor", enquanto ganham destaque os construtores e manipuladores dos objetos que carregam as marcas da cultura e induzem práticas que conformam sujeitos: arquitetos, impressores, editores.

\section{Considerações finais}

Em vista do exposto, cabe buscar na produção em tela, além de suas características mais definidoras e tendenciais, as variedades existentes e relativamente persistentes quanto à apropriação e ao uso de conceitos e ferramentas metodológicas e analíticas para os trabalhos que os congressistas submeteram aos eixos convenientes às ideias e aos intelectuais na história da educação. Para tanto, além de uma análise interna, faz-se necessário arguir pelos fatores externos, de diferentes naturezas e pesos, que teriam afetado, tanto a própria trajetória desse conjunto no eixo diacrônico das edições do evento, quanto os interesses, escolhas e modos de fazer que presidiram à elaboração das pesquisas originárias dos textos apresentados. É possível encontrar, quanto aos aspectos internos aos textos, a convivência entre modalidades tradicionais de abordagem do objeto e enfoques mais atualizados, bem como apropriações variadas da terminologia que envolve o conceito; quanto aos fatores extradiscursivos, devem ter peso quantitativo e qualitativo a trajetória de formação dos pesquisadores; o impacto institucional das relações de orientação, linhas e grupos de pesquisa; as relações e experiências internacionais dos pesquisadores; a descoberta ou formação de acervos documentais; o impacto das tendências gerais da expansão do sistema nacional de pós-graduação, tais como a regionalização e “interiorização" etc. No caso dos estudos sobre intelectuais, é provável que desse último fator venha resultando a prospecção e o surgimento de "intelectuais locais", para o tratamento dos quais se exercita de modo peculiar a transposição conceitual e procedimental dos estudos de referência.

Conclusivamente, sumario reflexões a serem futuramente exploradas por pesquisadores interessados na historiografia da educação brasileira e na história da formação deste campo. Em primeiro lugar, pode-se admitir que a temporada de balanços esteja superada. Os balanços panorâmicos, como modalidade de visada retrospectiva sobre a produção de pesquisa em história da educação brasileira, representaram o esforço necessário de expansão e diferenciação, que buscava visibilidade e autocompreensão, tanto quanto procedia à demarcação interna de posições 
e poderes institucionalizados. Os últimos balanços produzidos (SAVIANI et al., 2011) já exprimem com esmero a "pacificação", promovida pela Sociedade Brasileira de História da Educação, de uma comunidade que, em meados dos anos 1980, vivera os episódios da disputa acirrada entre duas tendências teórico-metodológicas concorrentes. Essa "pacificação", se é que houve, torna-se, ela mesma, uma questão interessante de pesquisa, pois cabe perguntar que efeitos a rarefação do debate trouxe ao desenho epistemológico atual. Um desses efeitos me parece ter sido a retração da historiografia como prática sistemática, posto que o respeito excessivo pela pluralidade tende a se desdobrar em mera tolerância ou desprezo pelo dessemelhante. Desse modo, ao pesquisador individual pouco interessaria discutir a acuidade e o valor epistemológico do conhecimento produzido fora de seus próprios marcos teóricos e metodológicos. O impacto dessa atitude é claro: as pesquisas se acumulam, mas o conhecimento não avança. Outra questão importante consiste em investigar, de modo diacrônico, se a propalada "mudança de paradigma" efetivamente impactou o tratamento de temas canônicos na especialidade desde os anos 1960-1970, e que atravessaram todo o período de desenvolvimento do campo. Isto só se poderá constatar mediante estudos verticais, tais como o que proponho. Finalmente, cabe se perguntar se, após viver um ciclo de mudanças políticas e epistemológicas, o campo de história da educação se acomodou em nichos especializados, que lutam em paralelo para garantir créditos e espaços de divulgação.

\section{Referências}

ALVES, C. M. C. Os resumos das comunicações e as possibilidades esboçadas no II Congresso LusoBrasileiro de História da Educação. In: SOUSA, C. P.; CATANI, D. B. (orgs.). Práticas educativas, culturas escolares, profissão docente. São Paulo: Escrituras, 1998. p.1 95-202.

ARAÚJO, M. M. A produção em história da educação das Regiões Nordeste e Norte. O estado do conhecimento (1982-2003). In: GONDRA, J. G. (org.). Pesquisa em história da educação no Brasil. Rio de Janeiro: DP \& A, 2005. p. 289- 312.

ASCOLANI, A. Los balances de la historia de la educación en Brasil: optimismo e incertidumbre de una producción expansiva. Comentarios en perspectiva comparada con Argentina y México. In:

NEPOMUCENO, M. A.; TIBALLI, E. F. A. (org.). A educação e seus sujeitos na história. Belo Horizonte: Argumentum, 2007. p.121-148.

BASTOS, M. H.; BENCOSTA, M. L. A.; CUNHA, M. T. S. A pesquisa em história da educação nos programas de pós-graduação em educação da Região Sul. In: GONDRA, J. G. (org.). Pesquisa em história da educação no Brasil. Rio de Janeiro: DP \& A, 2005. p. 243-287.

BASTOS, E.; RÊGO, W. (orgs.). Intelectuais e política. A moralidade do compromisso. São Paulo: Olho d'água, 1999. 
BONTEMPI JUNIOR, B. História da educação e história política. In: LINHALES, M. A.; FONSECA, T. N. L. Diálogos da história da educação. Ponta Grossa: Estúdio Texto, 2017. p. 39-56.

BONTEMPI JUNIOR, B. Laerte Ramos de Carvalho e a constituição da História e Filosofia da Educação como disciplina acadêmica. Uberlândia: Edufu, 2015.

BONTEMPI JUNIOR, B. História da educação brasileira: o terreno do consenso. 1995. 117p.

Dissertação (Mestrado em Educação) - Pontifícia Universidade Católica de São Paulo, São Paulo, 1995.

BOURDIEU, P. Coisas ditas. São Paulo: Brasiliense, 1990.

BURKE, P. Uma história social do conhecimento. De Gutemberg a Diderot. Rio de Janeiro: Zahar, 2003.

CATANI, D. B.; FARIA FILHO, L. M. Um lugar de produção e a produção de um lugar: história e historiografia da educação brasileira nos anos de 1980 e de 1990. In: GONDRA, J. G. (org.). Pesquisa em história da educação no Brasil. Rio de Janeiro: DP \& A, 2005. p. 85-110.

GONDRA, J. G. Historiografia da educação, seus balanços e saberes. A ultrapassagem como problema. In: NEPOMUCENO, M. A.; TIBALLI, E. F. A. (orgs.). A educação e seus sujeitos na história. Belo Horizonte: Argumentum, 2007. p. 163-179.

LE GOFF, J. Os intelectuais na Idade Média. Rio de Janeiro: José Olympio, 2003.

LECLERC, G. Sociologia dos intelectuais. São Leopoldo: UNISINOS, 2004.

LOPES, E.; GALVÃO, A. História da educação. Rio de Janeiro: DP\&A, 2001.

LÖWY, M. As aventuras de Karl Marx contra o Barão de Münchhausen. Marxismo e positivismo na sociologia do conhecimento. 5. ed. São Paulo: Cortez, 1996.

NAGLE, J. História da educação brasileira: problemas atuais. Em Aberto, Brasília, n. 32, p. 27-29, out. 1984.

NUNES, C.; CARVALHO, M. M. C. Historiografia da educação e fontes. In: GONDRA, J. G. (org.). Pesquisa em história da educação no Brasil. Rio de Janeiro: DP\&A, 2005. p. 17-62.

SAHLINS, M. História e cultura: apologias a Tucídides. Rio de Janeiro: Jorge Zahar, 2006.

SAVIANI, D. Apresentação. In: CONGRESSO BRASILEIRO DE HISTÓRIA DA EDUCAÇÃO, 1., 2000, Rio de Janeiro, RJ. Resumos [...]. Rio de Janeiro: Sociedade Brasileira da História da

Educação/Faperj/Prefeitura do Rio/CNPq/Fapesp, 2000. Disponível em:

http://sbhe.org.br/novo/congressos/cbhe1/apresentacao.htm. Acesso em: 22 ago. 2017.

SAVIANI, D. Os balanços na historiografia da educação brasileira: sentidos e perspectivas. In:

NEPOMUCENO, M. A.; TIBALLI, E. F. A. (orgs.). A educação e seus sujeitos na história. Belo Horizonte: Argumentum, 2007. p. 149-161.

SAVIANI, D. O debate teórico e metodológico no campo da história e sua importância para a pesquisa educacional. In: SAVIANI, D.; LOMBARDI, J. C.; SANFELICE, J. L. História e história da educação: o debate teórico- metodológico atual. Campinas: Autores Associados, HISTEDBR, 1998. p. 7-15.

SAVIANI, D. et al. Sociedade Brasileira de História da Educação: constituição, organização e realizações. Revista Brasileira de História da Educação, Campinas, v. 11, n. 3, p. 13-45, set./dez. 2011.

SIRINELLI, J-F. Os intelectuais. In: RÉMOND, R. (org.). Por uma história política. Rio de Janeiro: UFRJ/ FGV, 1996. 
VIEIRA, C. E.; GONDRA, J. G. Mapas da produção em história da educação. In: GONDRA, J. G. (org.). Pesquisa em história da educação no Brasil. Rio de Janeiro: DP\&A, 2005. p. 7-16.

VIEIRA, C. E. et al. Historiografia da educação no Brasil: contribuições da Sociedade Brasileira de História da Educação (SBHE). In: GONDRA, J. G.; MACHADO, M. C. G.; SIMÕES, R. H. S. (orgs.). História da educação, matrizes interpretativas e internacionalização. Vitória: Edufes, 2017. p. 11-20.

VIEIRA, C. E. História intelectual e história dos intelectuais: diálogos acerca da escrita da história da educação. In: VIEIRA, C. E.; STRANG, B. L. S.; OSINSKI, D. R. B. (orgs.). História intelectual e educação: trajetórias, impressos e eventos. Jundiaí: Paco Editorial, 2015. p. 11-26.

VIDAL, D. G.; FARIA FILHO, L. M. As lentes da história. Estudos de história e historiografia da educação no Brasil. Campinas: Autores Associados, 2005.

VEYNE, P. Os conceitos em História. In: SILVA, M. B. N. (org.) Teoria da história. São Paulo: Cultrix, [s/d.], p. 120-134.

WARDE, M. J. Anotações para uma historiografia da educação. Em Aberto, Brasília, n. 32, p. 1-6, out. 1984.

WEBER, M. A “objetividade” do conhecimento nas ciências sociais. In: COHN, G. (org.). Weber. 7. ed. São Paulo: Ática, 2000. p. 79-127.

XAVIER, L. Particularidades de um campo disciplinar em consolidação: balanço do I Congresso Brasileiro de História da Educação (RJ/2000). In: SBHE (Org.). Educação no Brasil. Campinas: SBHE, Autores Associados, 2001. 